\title{
Uma Reflexão sobre as Reduções Jesuíticas Orientais: Do Apogeu a Derrocada Final
}

\author{
Una Reflexión sobre las Reducciones Jesuíticas Orientales: Del Apogeo al \\ Derrocamiento Final
}

\author{
A Reflexion on the Eastern Jesuitical Reductions: From the Apogee to the Final \\ Debacle
}

José Luciano Gattiboni Vasques ${ }^{1}$

\begin{abstract}
Resumo
Uma Reflexão sobre as Reduções Jesuíticas Orientais: Do Apogeu a Derrocada Final, nos instiga a pensar e entender toda esta estrutura que foi sendo construída dentro de uma região inóspita e ao mesmo tempo relevante para a economia Ibérica. $\mathrm{O}$ estudo que se pretende mostrará como este processo histórico foi montado e de que maneira o guarani participou e como isso influiu no seu modo de vida. Este estudo mostra a razão das fundações da Colônia do Santíssimo Sacramento e dos Sete Povos das Missões Orientais, quais seus objetivos e os recursos utilizados para alcançá-los, também esclarecem os principais argumentos para a efetivação do Tratado de Madrid (1750) e a posterior reação dos povoados missioneiros em relação a dito Tratado, suas tentativas de se manterem no território, em primeiro lugar através de acordos para a permanência e após a negativa por parte das Coroas ibéricas partindo para o confronto armado, não levando em conta suas escassas estruturas bélicas, razão pela qual teve grande parte de seus guerreiros dizimados e os povoados destruídos. Chegando à conclusão de que em nome de uma tentativa de se resolver os problemas entre Portugal e Espanha, o Tratado de Madrid provocou ainda mais desavenças entre eles.
\end{abstract}

Palavras-chave: Redução; Guarani; Jesuíta; Portugal; Espanha.

\section{Resumen}

Una reflexión sobre las Reducciones Jesuíticas Orientales: del apogeo al derrocamiento final, nos instiga a pensar y entender toda esta estructura que fue construida dentro de una región inhóspita y al mismo tiempo relevante para la economía Ibérica. El estudio que se pretende mostrará cómo este proceso histórico fue montado y de qué manera el guaraní participó y cómo eso influyó en su modo de vida. Este estudio muestra la razón de las fundaciones de la Colonia del Santísimo Sacramento y de los Siete Pueblos de las Misiones Orientales, cuáles sus objetivos y los recursos utilizados para alcanzarlos, también esclarecen los principales argumentos para la efectivación del Tratado de Madrid (1750) y la posterior la reacción de los pueblos misioneros en relación a dicho Tratado, sus intentos de mantenerse en el territorio, en primer lugar a través de acuerdos para la permanencia y después de la negativa por parte de las Coronas ibéricas partiendo hacia el enfrentamiento armado, no teniendo en cuenta sus escasas estructuras bélicas, por lo que tuvo gran parte de sus guerreros diezmados y los pueblos destruidos. Llegando a la conclusión de que en el nombre de un intento de resolver los problemas entre Portugal y España, el Tratado de Madrid causó aún más la discordia entre ellos.

Palabras claves: Reducción; guaraní; jesuita; Portugal; España.

Abstract

\footnotetext{
${ }^{1}$ Especialista em Imagem, História e Memória das Missões: Educação para o Patrimônio pela Universidade Federal do Pampa, Campus São Borja, Rio Grande do Sul, Brasil; professor no Instituto Estadual Padre Francisco Garcia, São Borja, Rio Grande do Sul, Brasil; bolsista supervisor do Pibid (Sub-projeto de História). Acadêmico do curso de Ciências Humanas Licenciatura - Unipampa Campus São Borja, Rio Grande do Sul, Brasil. Email:lugatvasques@gmail.com.
} 
A Reflexion on the Eastern Jesuitical Reductions: From the apogee to the final debacle, instigates us to think and understand all this structure that was being built within an inhospitable region and at the same time relevant to the Iberian economy. The study is intended to show how this historical process was set up and how the Guaraní participated and how it influenced their way of life. This study shows the reasons for the foundations of the Colony of the Blessed Sacrament and of the Seven Peoples of the Eastern Missions, and its objectives and the resources used to reach them. They also clarify the main arguments for the implementation of the Treaty of Madrid (1750) the reaction of the missionary villages in relation to this Treaty, their attempts to remain in the territory, firstly through agreements for the permanence and after the refusal by the Iberian Crowns leaving for the armed confrontation, not taking into account their scarce military structures, for which reason a great part of his warriors decimated and the villages destroyed. Coming to the conclusion that in the name of an attempt to solve the problems between Portugal and Spain, the Treaty of Madrid provoked still more disagreements between them.

Keywords: Reduction; Guarani; Jesuit; Portugal; Spain.

\section{INTRODUÇÃO}

A história das disputas pelas fronteiras ${ }^{2}$ do Sul do Continente Americano foram marcadas pelos constantes enfrentamentos entre as Coroas portuguesa e espanhola. É neste jogo de interesses ibéricos que vamos focalizar e analisar as ações geopolíticas empreendidas no final do século XVII, abrangendo também o século XVIII no processo colonial e suas posteriores consequências na população nativa.

A partir da fundação da Colônia do Santíssimo Sacramento (1680), em que os portugueses, avançam em terras "tidas" como espanholas, abre-se a necessidade de haver por parte de Espanha, um cuidado maior em relação as suas fronteiras platinas.

O processo expansionista português possibilitou momentos distintos em relação à implantação do sistema missional, pois existiram duas fases deste processo histórico na atual área do Estado do Rio Grande do Sul:

A Primeira Fase Reducional Missioneira deu-se com a fundação de São Nicolau (1626) pelo Padre Roque Gonzáles, que depois de investidas dos bandeirantes paulistas que vinham à região com o intuito de capturar os Guarani para posterior venda no mercado escravagista, viram-se obrigados a fugir para o lado oeste do rio Uruguai, abandonando o gado vacum que ficou solto no território, e se multiplicou, formando vastos rebanhos.

A Segunda Fase Reducional Missioneira, a mais significativa em razão do longo período em que esteve presente e em plena organização social, política, econômica e religiosa

\footnotetext{
${ }^{2} \mathrm{Na}$ história da fronteira rio-grandense, a fixação da linha divisória, sua afirmação ou suas oscilações, em épocas diferentes, apesar das operações concretamente regionais, dependeram de decisões acordadas politicamente nos centros de decisão de poder, a exemplo do Rio de Janeiro, Lisboa, Madrid, Londres, Buenos Aires e Montevidéu. Combinados com a conquista militar, a expansão demográfica e o recorrente do uti possidetis, ao cabo, a sua definição significou uma opção imaginária, arbitrária, pesada na balança limitativamente possível da geopolítica. GOLIN, Tau. A Fronteira. Porto Alegre: L\&PM, 2002, p.13.
} 
na região Sul do Continente Americano, iniciou-se com a fundação de São Francisco de Borja (1682?), (re)conhecido como o "Primeiro dos Sete Povos das Missões Orientais" e perdurou até o epílogo missioneiro proveniente da Guerra Guaranítica.

Neste estudo, objetiva-se compreender todo o jogo político entre as nações ibéricas, pois Portugal após o fim da União Ibérica $^{3}$, havia perdido o direito da livre navegação na região do Prata, e o príncipe-regente D. Pedro, tinha interesse na expansão do território português, em razão deste local ser de importância ímpar, para continuar captando principalmente a prata contrabandeada de Potosi (Peru), portanto é neste contexto que surgem novos cenários e conflitos entre os lusitanos e espanhóis.

\section{A COLÔNIA DO SANTÍSSIMO SACRAMENTO}

Portugal e Espanha além de limítrofes, e de papel de destaque nas Grandes Navegações, razão de possuírem diversas colônias espalhadas pelo planeta, e que acabaram por propiciar e gerar muitos conflitos entre ambos, relacionados as questões de seus limites, porém, nada comparável como os ocorridos em virtude da fundação da pequena Colônia do Santíssimo Sacramento ${ }^{4}$, estabelecida às margens do rio da Prata ${ }^{5}$, bem defronte a Buenos

\footnotetext{
${ }^{3}$ Em 1580, instalou-se uma crise sucessória em Portugal. 1578, o rei Dom Sebastião I morrera na batalha de Alcácer Quibir, no Marrocos contra os mouros, no norte da África, não deixando herdeiros. Assumira o trono português, como regente, o cardeal Dom Henrique, seu tio-avô, que morreu em 1580. Extinguia-se com ele a dinastia de Avis. Vários candidatos, por ligações de parentesco, apresentaram-se para a sucessão. Felipe II, rei da Espanha, por ser neto de Dom Manuel, o Venturoso, e tio de D. Sebastião, julgava-se o candidato com mais direito do trono português. Assim, as forças espanholas invadiram Portugal, em 1580, e Felipe II tomou a Coroa portuguesa, unindo Portugal a Espanha. Este fato ficou conhecido como União Ibérica, que se estendeu até 1640.
}

www.multirio.ri.gov.historia/modulo01/união iberica.html. Acesso em 07/08/2017.

${ }^{4}$ Colônia do Santíssimo Sacramento. Atual cidade de Colônia, Uruguai. Fundada pelo português d. Manuel Lobo (?-1683), em janeiro de 1680, sob a orientação da Coroa lusitana. Localizada no estuário do Prata, em frente a Buenos Aires, este enclave fincado no território castelhano foi palco de inúmeros conflitos entre portugueses e espanhóis. Centro de comércio e contrabando. A Colônia foi tomada quatro vezes pelos espanhóis: a) 7 de agosto de 1680; devolvida em 14 de fevereiro de 1683, por determinação do Tratado de Lisboa, de 7 de maio de 1681 ; b) 16 de março de 1705, reentregue em 4 de março de 1716, conforme prescrição do Tratado de Utrecht, de 6 de fevereiro de 1715; c) 25 de setembro de 1761, restituída em 29 de dezembro de 1763, por previsão do Tratado de Paris, de 10 de fevereiro do mesmo ano. Ocupada definitivamente, em sua quarta vez, em 3 de junho de 1777. Permaneceu como possessão espanhola pelo Tratado de Santo Ildefonso, de primeiro de outubro (Golin, Zero Hora, 13 de janeiro de 1993; Sá, 1993;

Monteiro, 1937; Assunção, 1985). GOLIN, Tau. A guerra guaranítica: como os exércitos de Portugal e Espanha destruíram os Sete Povos dos jesuítas e índios guaranis no Rio Grande do Sul / Tau Golin. - 2.ed. - Passo Fundo: EDIUPF; Porto Alegre: Ufrgs, 1999, p.150. 
Aires, e que segundo os limites vigentes do Tratado de Tordesilhas (1750), ficava dentro de território "dito" espanhol, e que Portugal tentava impor ardilosamente em cortes internacionais, a cartografia portuguesa ${ }^{6}$, onde constava que a possessão portuguesa na América seria delimitada, ao norte, pela foz do rio Amazonas e, ao sul, pela foz do rio da Prata.

Os constantes conflitos entre as Coroas Ibéricas, em virtude de disputas territoriais e econômicas na região platina, e a contínua tentativa expansionista portuguesa de suas fronteiras, pois era imperativo marcar presença naquela área, em razão da sua importância comercial e estratégica na margem setentrional do estuário do rio da Prata, contextualizou o surgimento da Colônia do Santíssimo Sacramento.

O príncipe-regente Dom Pedro, em virtude de seus interesses geopolíticos tinha interesse na expansão do território da Colônia portuguesa até o estuário do rio da Prata, em função de que a partir dessa nova alternativa, voltaria a ter restabelecido os vínculos com a região do Prata, rompidos ao final da União Ibérica (1640), e que favoreceram por um bom tempo os portugueses, possibilitando a penetração num território que, por "direito", pertencia aos espanhóis, pois através dela possibilitaria continuar captar a prata contrabandeada, oriunda de Potosi (Peru) com destino ao porto de Buenos Aires. Já Monteiro, descreve que:

D. Pedro II, rei de Portugal (1668-1706), ordenou ao Tenente-General Jorge Soares de Macedo que estudasse a costa do rio da Prata, escolhendo local para a fortificação e povoação. Em 1678 Jorge Soares escreveu ao rei que não partiu do Rio de Janeiro devido ao mau tempo e à chegada de D. Manuel Lobo, o novo governador. ${ }^{7}$

No entendimento de Arno Kern, o contexto assume outra importância uma vez que: No final do século, em 1680, o povoamento da região seria estabelecido oficialmente com a fundação, pelo governador Manoel Lobo, do Rio de Janeiro, da polêmica Colônia do Sacramento, no Sul do atual Uruguai. ${ }^{8}$

\footnotetext{
${ }^{5} \mathrm{O}$ rio da Prata foi descoberto em 1514, pelo português Nuno Manuel, mas somente em 22 de março de 1516 foi conquistado por Juan Díaz de Solis, rio este tido como porta principal de entrada para as riquezas oriundas do Peru, e em razão disto sendo o mais importante ponto da costa meridional da América do Sul.

${ }^{6}$ A cartografia portuguesa, desde o século XVI, colocava a foz do rio Amazonas e o rio da Prata no mesmo meridiano, incluindo a bacia platina em território lusitano, diminuindo em graus a distância que separava a América da África, conforme os mapas de Bartolomeu Velho, feitos em Lisboa em 1561, o de Luís Teixeira, em 1574, e o de João Teixeira Albernás, em 1666. Em 1676, cedendo às pressões portuguesas, o Papa Inocêncio IX estendeu o bispado do Rio de Janeiro até o rio da Prata, assegurando a posse das terras doadas aos Correia de Sá. FLORES, Moacyr. Colonialismo e missões jesuíticas. Porto Alegre: EST/Instituto de Cultura Hispânica do Rio Grande do Sul, 1983, p. 56.

${ }^{7}$ MONTEIRO, Jonathas da Costa Rego. A Colônia do Sacramento. Porto Alegre: Globo, 1937. I vol. p. 98 a 108.

${ }^{8}$ KERN, Arno Alvarez. Missões: uma utopia política. Série Documenta 14. Porto Alegre: Mercado Aberto, 1982. p. 157.
} 
Ao revisar de Moacir Flores a conjuntura assume uma importância sem igual, pois: D. Manuel Lobo trouxe instruções específicas para formar o novo estabelecimento português na margem esquerda do Prata, que gerou conflitos entre portugueses e espanhóis, de 1680 a $1777 .{ }^{9}$

Nesta linha de argumentação, FLORES (1983) concluí que, “o Papa Inocêncio IX em 1676, acabou cedendo às pressões da Coroa portuguesa e estendeu o bispado do Rio de Janeiro até o rio da Prata, o que assegurou a posse das terras doadas aos Correia de Sá. Faltava então para garantir estes direitos a construção de uma cidadela e povoação do local”. Segue ainda Flores, "no ano seguinte a decisão do Papa, Salvador Correia de Sá solicitou licença para a construção de uma cidadela fortificada na ilha São Gabriel, chegando inclusive indicar três lugares para a construção da mesma". Todo este contexto, ocorrido a partir da ruptura entre as coroas ibéricas abriu-se a necessidade de uma solução por parte de Portugal que resultasse na quebra do monopólio espanhol na região em virtude da utilização do sistema de portos únicos, onde somente podiam navegar em seus territórios embarcações com bandeira de Espanha.

O Tenente-General Jorge Soares de Macedo recebeu ordens do rei de Portugal, D. Pedro II, para que este através de estudos na região do rio da Prata encontrasse um lugar adequado para que fosse providenciada a construção de um forte e ao mesmo tempo possibilitasse a criação de um povoado português na dita região em questão.

A fundação da Colônia do Santíssimo Sacramento, o entreposto comercial de Portugal no estuário do rio da Prata, acabou dificultando ainda mais as relações da Metrópole portuguesa com a Espanha. A tumultuada Colônia do Santíssimo Sacramento, que Portugal manteve durante um período de quase cem anos (1680 a 1777), várias vezes foi capitulada, destruída e devolvida pelas forças espanholas aos portugueses através de diversos tratados realizados em cortes arbitrárias entre as Coroas Ibéricas.

Portugal em razão de que Companhia de Jesus e os Guarani, por diversas vezes haviam lutado ao lado de Espanha nos conflitos platinos, aliando ao contexto da não

\footnotetext{
${ }^{9}$ FLORES, Moacyr. Colonialismo e Missões Jesuíticas. Porto Alegre: EST / Instituto de Cultura Hispânica do Rio Grande do Sul, 1983, p. 57.
} 
permissão da entrada de colonos, e conseguido que fosse proibido a escravização indígena, adquiriram vários inimigos, entre eles o mais incisivo: o marquês de Pombal ${ }^{10}$.

\title{
3. AS MISSÕES JESUÍTICAS
}

A Companhia de Jesus, fundada por Ignácio de Loyola ${ }^{11}$, foi a alternativa espanhola encontrada para colonizar o território e impedir o avanço português rumo a Potosi. Cada redução era estruturada economicamente em duas partes: o abambaé, que era a propriedade do homem, onde cada família trabalhava para o seu sustento, e o tupambaé, que era a propriedade de Deus, onde os filhos solteiros trabalhavam junto com seus pais, destinado ao sustento da comunidade. Nesta propriedade estavam incluídos além dos campos cultivados, os ervais $^{12}$, as estâncias, local onde eram criados os rebanhos, e que, serviam para realização do pagamento dos impostos com a Fazenda Real; para suprir as necessidades decorrentes da

\begin{abstract}
${ }^{10}$ Marquês de Pombal é o nome com que ficou conhecido Sebastião José de Carvalho e Melo, político e verdadeiro dirigente de Portugal durante o reinado de José I, o Reformador. Pombal nasceu em Lisboa no dia 13 de maio de 1699. Estudou na Universidade de Coimbra. Em 1738, foi nomeado embaixador em Londres e, cinco anos depois, embaixador em Viena, cargo que exerceu até 1748. Em 1750, o rei José nomeou-o Secretário de Governo (ministro) para Assuntos Exteriores. Quando um terremoto devastador destruiu Lisboa em 1755, Pombal organizou as forças de auxílio e planejou a reconstrução da cidade. Foi nomeado primeiroministro neste mesmo ano. A partir de 1756, seu poder foi quase absoluto e realizou um programa político de acordo com os princípios do Século das Luzes ou lluminismo. Aboliu a escravidão, reorganizou o sistema educacional, elaborou um novo código penal, introduziu novos colonos nos domínios coloniais portugueses e fundou a Companhia das Índias Orientais. Além de organizar o Exército e fortalecer a Marinha portuguesa, desenvolveu a agricultura, o comércio e as finanças, com base nos princípios do mercantilismo. No entanto, suas reformas suscitaram grande oposição, em particular dos jesuítas e da aristocracia. Quando ocorreu o atentado contra o rei em 1758, conseguiu implicar os jesuítas, expulsos em 1759, e os nobres. Alguns destes foram torturados até morrer. Em 1770, o rei lhe concedeu o título de marquês. Depois da morte do rei José I, foi condenado por abuso de poder. Expulso da Corte, retirou-se para sua propriedade rural em Pombal, onde faleceu no dia 8 de maio de 1782. www.netsaber.com.br/biografias/ver_biografia_c_891.html.
\end{abstract}

${ }^{11}$ Soldado por herança e vocação, o espanhol Ignácio de Loyola, nascido em 1491, abandonou a carreira das armas quando, convalescendo de um ferimento recebido na guerra entre Espanha e França, leu uma Vida de Cristo. Apesar de manco, tornou-se um peregrino incansável. Em 1539, depois de ter ido à Terra Santa e de ser duas vezes preso pela Inquisição, decidiu fundar a Companhia de Jesus. Estabeleceu um modelo militarizado para a ordem, imaginado como um grupo de combate à Reforma. O Brasil foi a primeira província além-mar da companhia. Morto em 1557, Loyola foi canonizado em 1622. História do Brasil/Zero Hora/ RBS/1998. p.33.

12 A produção de erva-mate era de suma importância, já que o produto era utilizado no pagamento dos tributos devidos pelos Guarani missioneiros à Coroa de Espanha, estabelecidos pela Cédula Real de 1661. Mesmo que as Reduções, por orientação administrativa, devessem ser auto-suficientes, intentando-se sempre a autonomia econômica, existiam alguns produtos que deveriam ser buscados nos mercados de Santa Fé e Buenos Aires. Nessa atividade, a erva-mate assumia um papel importante, representando a moeda das reduções na aquisição daquilo que, em seu espaço, não era produzido. GOMES, Roselene Moreira; QUEVEDO, Júlio. São Nicolau. Porto Alegre: Martins Livreiro, 2003, p.54. 
manutenção e obras nas reduções jesuíticas. Novamente FLORES (1983) descreve os povoados da seguinte forma:

O núcleo urbano da cada um dos Sete Povos (Pueblos) distribuía-se em torno de uma grande praça central, a qual servia para as comemorações, exercícios militares e procissões. Em cada canto havia uma cruz que marcava local de oração ou de procissão. No lado sul da praça, de onde soprava o vento frio, alinhavam-se as oficinas, o colégio, o templo, o cemitério e o cotiguaçu. Atrás destes edifícios localizavam-se o pomar e a horta, onde os meninos aprendiam técnicas agrícolas e produziam alimentos para os alunos, os doentes do hospital e as mulheres do cotiguaçu ${ }^{13} \cdot{ }^{14}$

As primeiras reduções na América do Sul - San Ignácio e Loreto - foram fundadas em 1609 e marcaram o início da Primeira Fase das missões guaraníticas que se estendeu até 1641, quando os Guarani, segundo CAMARGO (1996), foram autorizados pelo decreto real de 21 de maio de 1640, para enfrentar os bandeirantes paulistas a utilizar armas de fogo, que sob o comando de Raposo Tavares ${ }^{15}$, rumavam para as Missões Orientais e vencendo-os na batalha de M'bororé ${ }^{16}$.

Todas as Missões seguiam as normas estabelecidas pelas monarquias ibéricas e pelo papado, e que segundo KERN “não se pode desconhecer a centralização das decisões tanto a

\footnotetext{
${ }^{13}$ Cotiguaçu era a casa das mulheres viúvas e desamparadas. Ali as moças aprendiam a bordar, costurar e a fazer rendas semelhantes às europeias.

${ }^{14}$ FLORES, 1983. op. cit., p. 26.

${ }^{15}$ Antônio Raposo Tavares nasceu em Portugal por volta de 1598, vindo para o Brasil no ano de 1618, pois seu pai era governador da capitania de São Vicente. Iniciou suas expedições, conhecidas como despovoadoras, em 1627, atacando primeiramente Guairá e, em 1636, o Tape. Teve alguns cargos públicos e chefiou a expedição que chegou até o atual estado do Pará, levando três anos para tanto. Faleceu na cidade de São Paulo no ano de 1658. Disponível em: <httpd://www.submarino.net/jubileu/raposo_tavares.htm>. Acesso em: 26 dez. 2002. COLVERO, Ronaldo. Negócios na madrugada: o comércio ilícito na fronteira do Rio Grande do Sul. Passo Fundo: UPF, p. 20.

${ }^{16}$ A Batalha de M'bororé foi uma batalha ocorrida em 11 de março de 1641 na América do Sul vencida pelos guaranis. Esta foi a batalha mais relevante da história da América colonial e constitui um episódio importante na história dos Trinta Pueblos (Reduções) do Paraguai. Uma bandeira de escravistas paulistas com três mil homens adentrou o território das reduções com a finalidade de destruir definitivamente as missões jesuíticas e cortar as vias de comunicação espanholas entre os povoados paraguaios e o Alto Peru. Os guaranis, avisados por sentinelas avançados, preparam-se para receber os atacantes. Na confluência entre o rio Uruguai e o rio M'bororé, na atual província de Misiones na Argentina, os bandeirantes paulistas foram derrotados por um exército de guaranis - organizado pelos jesuítas - de cerca de quatro mil homens. Morreram na batalha mais de dois mil homens. O episódio foi decisivo para o futuro da província paraguaia que, graças aos guaranis, permaneceu assim sob o controle da Espanha. Depois desta batalha as incursões de bandeirantes paulistas foram cada vez mais raras e menos agressivas. De sua parte os jesuítas continuaram a manter uma força armada, com plena autorização da coroa espanhola, que se dera conta da eficácia e da importância do exército guarani e da necessidade estratégica das Reduções.
} 
nível da monarquia espanhola, que controlava a clero católico através da instituição do real patronato" 17 .

Quando da vinda da Companhia de Jesus ${ }^{18}$, para a região do Prata no início do século XVII, que se objetivara num primeiro momento em converter e apaziguar os Guarani que constantemente entravam em conflitos com os encomendeiros ${ }^{19}$ espanhóis, para posteriormente serem designados "os guardiões das fronteiras", em virtude da falta de contingentes militares para guardá-la, e em relação ao trabalho missional, os inacianos já possuíam experiência em povoados indígenas tanto nas Américas, como em outros continentes.

Esse acúmulo de experiência colonialista, aliado a condições sociais geográficas e históricas, possibilitou que, em menos de vinte e cinco anos, os jesuítas desenvolvessem mais de trinta Missões na região. Essas Missões apesar de não conseguirem estabelecerem-se em territórios contínuos, devido à rebeldia incessante das nações indígenas Güenoas, Jaros, Minuanos e Charruas, do Alto Uruguai, chegaram a abranger $350.0000 \mathrm{Km}^{2}$. Todas, no entanto, sob a administração da Província Jesuítica do Paraguai, pertencente ao Vice-Reinado do Peru, pois na época, como sabemos, o trono de Portugal estava submetido ao da Espanha, não havendo fronteiras entre ambos, mas apenas as linhas teóricas e imprecisas do tratado de Tordesilhas, que indicavam a procedência lusa ou hispânica de cada província. ${ }^{20}$

Suas experiências anteriores propiciaram que num curto espaço de tempo, os jesuítas implantassem e desenvolvessem trinta povoados missioneiros na região sul do Continente Americano. As Missões, em razão da rebeldia de alguns povos indígenas, tais como: Guenoas e Minuanos, não conseguiram estabelecer-se em áreas continuas, mas abrangeram grandes áreas territoriais.

\footnotetext{
${ }^{17}$ KERN, Arno Alvarez. Utopia e missões jesuíticas. Porto Alegre: Ed. Universidade/UFRGS, 1994. p. 60. (Síntese Universitária; 40).

${ }^{18} \mathrm{Em} 1540$ a Companhia foi aprovada pelo Papa e sempre esteve impregnada pelo lema de seu fundador Ignácio de Loyola "Ficar no mundo, servindo ao próximo, mesmo com a incerteza de se salvar", já os primeiros jesuítas chegaram ao Peru em 1567, onde fundaram a Redução de Juli.

${ }^{19}$ Os encomendeiros recebiam da corte espanhola terras e certa quantidade de índios, para que explorassem as terras e cristianizassem os nativos.

${ }^{20}$ GOULART, Cátia Rosana Dias. Uma Leitura de A Cidade dos Padres no Contexto do Novo Discurso FiccionalHistórico na América Latina. Fundação Universidade Federal do Rio Grande: 2004, p. 78.
} 
Todos os Trinta Povos tinham como administrador central, a Província do Paraguai, pertencente ao Vice-Reinado do Peru, já que neste momento Portugal ${ }^{21}$ encontrava-se sob a tutela administrativa e política de Espanha, e, portanto não havia limites entre ambos, separando-os apenas a linha imaginária do Tratado de Tordesilhas ${ }^{22}$. Em relação a localização dos povoados BRUXEL (1987, p. 25) explica: "Portanto, a localização das Reduções não obedeceu a interesses políticos e nacionalistas, mas para a defesa das fronteiras",

Por volta de 1680, contudo, os jesuítas mais uma vez se estabeleceram na região, desta vez na área confinada pelos rios Ibicuí e Uruguai, catequizando os indígenas, e fundando várias missões. Foram chamados Sete Povos das Missões Orientais do Uruguai, localizados no oeste do Rio Grande do Sul atual. $^{23}$

A Geopolítica Platina no período colonial esteve fortemente marcada pelas disputas territoriais entre as Coroas Ibéricas. Estas se caracterizaram não apenas por interesses mercantis, mas também por relações de poder que extrapolaram os limites fronteiriços definidos pelos tratados.

É nesse jogo de interesses ibéricos que a segunda fase da ação missional jesuítica se estabelece, a leste do rio Uruguai, no final do século XVII.

A partir da fundação da Colônia do Santíssimo Sacramento (1680) - entreposto comercial português criado em terras tidas como espanholas - onde o trabalho jesuítico de evangelização do nativo Guarani, através da organização de um cordão de reduções capazes de barrar o avanço português, novamente passa a ser a melhor opção a coroa da Espanha, que não dispunha de efetivos próprios e suficientes para povoar e garantir a posse de tão vasta e importante área.

É neste contexto geopolítico que foram fundados os Sete Povos das Missões Orientais: São Francisco de Borja, São Nicolau, São Luiz Gonzaga, São Miguel Arcanjo, São Lourenço Mártir, São João Batista, Santo Ângelo Custódio.

\footnotetext{
${ }^{21}$ Com a morte, em 1578, de D. Sebastião, rei de Portugal, quando dá expulsão no norte da África dos árabes assume, seu herdeiro mais próximo, que falece em 1580, quando assume Felipe II, rei de Espanha, tio de D. Sebastião, permanecendo no poder até 1640, quando termina a União Ibérica.

22 Em 1493, o papa Alexandre VI criou um documento chamado Bula. Nesse documento, ficava estabelecido que as terras situadas até 100 léguas a partir das ilhas de Cabo Verde seriam de Portugal e as que ficassem além desta linha seriam da Espanha. O medo que Portugal tinha de perder o domínio de suas conquistas foi tão grande que, por meio de forte pressão, o governo português convenceu a Espanha a aceitar a revisão dos termos da bula e assinar o Tratado de Tordesilhas (1494). De acordo com o Tratado de Tordesilhas, as terras, situadas até 370 léguas a oeste de Cabo Verde pertenciam a Portugal, e as terras a oeste desta linha pertenciam a Espanha. www.ig.com.br. Acesso 29/08/2017.

${ }^{23}$ KERN, 1994. op. cit., p. 168.
} 
A partir de então, verifica-se uma nova fase de construção e dinamização das espacialidades ao longo dos rios Uruguai, Piratini e Ijuí. Caracterizado pela produção de elementos paisagísticos mais duradouros que consolidaram as reduções como importantes centros de produção econômica, cultural e social, além de representarem a tentativa de afirmação política do colonialismo espanhol na região.

A primeira das reduções que surgem no lado esquerdo do Rio Uruguai é a de São Francisco de Borja, a qual teve origem a partir do século XVII, entre 1682 e 1690, algo que os novos historiadores discutem ${ }^{24}$. Esta redução teve início a partir do desmembramento de parte da população do povoado de São Tomé, povoado que ficava localizado no lado direito do rio Uruguai. O padre Francisco Garcia do Prada juntamente com guaranis oriundos da redução vizinha (Argentina), fundou a dita redução, dando início a nova fase reducional.

O Tratado de Madrid é o marco principal como fator de desconstrução do espaço reducional missioneiro, pois a partir do acordo ocorrido entre as Coroas Ibéricas, mais precisamente entre D. João V, rei de Portugal e Fernando VI, rei de Espanha, no qual trocavam a Colônia do Santíssimo Sacramento pelos Sete Povos das Missões Orientais, onde o mais traumático foi à ordem para que todos, índios reduzidos e jesuítas, juntamente com os pertences que pudessem carregar, iniciassem a transferência para o outro lado do rio Uruguai.

\section{O TRATADO DE MADRID}

O Tratado de Madrid (1750) surgiu num contexto, em que os reis de Portugal e de Espanha, tentavam pôr fim a algumas questões que seguidamente entravam em divergências no hemisfério sul do Continente Americano: as questões relativas às suas fronteiras, que apesar de estar em vigência o Tratado de Tordesilhas, que estabelecia e determinava a posse

\footnotetext{
${ }^{24}$ O problema fundacional de São Borja já não é de hoje que chama a atenção dos investigadores. Os autodidatas em especial, sustentaram a hipótese por pelo menos três décadas. Ao que se tem conhecimento, o jurista Aurélio Porto (1954) foi o pioneiro de tal versão, todavia o contexto passa a ganhar forma aos idos de 1982 por meio do então folclorista Aparício Silva Rillo que passa a disseminar a informação com vistas a aproximar a municipalidade de São Borja para as arenas de debate missioneiro. Tudo indica que tal intenção foi dirigida de modo a fazer com a localidade se adequasse as comemorações festivas dos 300 anos do sítio histórico de São Miguel - em 1987. Daquele evento aos dias de hoje, a versão "Primeiro dos Sete Povos", vem sendo confrontada por historiadores que passaram a reivindicá-la como 1690. Das versões apresentadas, cabe recorrer: MAURER, Rodrigo. Do um que não sete: o caso da antiga redução de San Francisco de Borja e a dinâmica da diferença. PPG em História UPF, 2011. PINTO, Muriel \& MAURER, Rodrigo. Quando a geo-história avança sobre os significados de um espaço-urbano: as paisagens culturais e as transformações identitárias da fronteira Brasil-Argentina. In: Eure. Vol. 40, n. 120. 2014.
} 
das terras entre as Coroas Ibéricas, mas que segundo Porto ${ }^{25}$, esta tentativa de estabelecer os limites acordados no Tratado de Madrid assinalou "o início da fase de decadência da civilização jesuítica nas Missões Orientais do Uruguai”.

Das povoações ou aldeias, que cede Sua Majestade Católica, na margem Oriental do rio Uruguai, sairão os Missionários com todos os móveis e efeitos, levando consigo os índios para os aldear em outras terras da Espanha; e os referidos índios poderão levar também todos os seus bens móveis e semoventes, e as armas, pólvora e munições, que tiverem. Em cuja forma se entregarão as povoações à Coroa de Portugal, com todas as suas casas, igrejas e edifícios, e a propriedade e posse do terreno. As que se cedem por Suas Majestades Fidelíssima e Católica nas margens dos rios Pequirí, Guaporé e das Amazonas se entregarão com as mesmas circunstâncias que a Colônia do Sacramento, conforme se disse no Artigo XIV. E os índios, de uma e outra parte, terão a mesma liberdade, para se irem ou ficarem, do mesmo modo e com as mesmas qualidades que o hão de poder fazer os moradores daquela Praça; exceto que os que se forem, perderão a propriedade dos bens de raiz, se os tiverem. ${ }^{26}$

O Tratado de Madrid, segundo seus artigos, explicitava a maneira de como deveria ocorrer as mudanças para que se fizessem cumprir todas as partes do acordado. Mas a obrigatoriedade de abandonarem suas povoações e retornarem mais uma vez para o outro lado do rio Uruguai, levando o gado e tudo àquilo que conseguissem carregar, móveis e semoventes ao território localizado a oeste do rio Uruguai, atual Argentina.

(...) os luisistas iniciaram a segunda transmigração, (...). Passaram por Santo Tomé, rumo ao sul. (...), quando os charruas impediram o avanço, (...). Estes infiéis atacaram os postos da Estância de Japeju, afirmando que eram terras de seus avós. O corregedor de São Luís, temeroso de uma guerra com os charruas, retornou novamente ao antigo povoado. ${ }^{27}$

Alguns dos povos missioneiros chegaram a deslocar-se para o novo território, sendo de lá repelidos por índios charruas. A redução de São Nicolau não aceitou esta nova determinação e rebelou-se, fato esse, que levou outras reduções a seguí-la e impor uma forte resistência aos termos acordados no Tratado, é quando os Guarani decidiram assumir a responsabilidade dos ataques contra as tropas portuguesas e espanholas.

\footnotetext{
${ }^{25}$ PORTO. op.cit. p. 422.

${ }^{26}$ GOLIN, Tau. A Guerra Guaranítica: como os exércitos de Portugal e Espanha destruíram os Sete Povos dos jesuítas e índios guaranis no Rio Grande do Sul (1750-1761). Passo Fundo/Porto alegre: EDIUPF/Editora da Universidade - UFRGS, 1999, p. 552-553.
}

${ }^{27}$ FLORES, 1983. op.cit., p.73. 
A assinatura do Tratado de Madrid tinha como objetivo central cessar às disputas territoriais luso-espanholas na América, promovendo a troca da Colônia do Santíssimo Sacramento pelas Missões Orientais, em que Portugal, ao fundar Sacramento, dentro de território espanhol, objetivava obter e manter a livre navegação no rio da Prata.

O diplomata paulistano Alexandre de Gusmão ${ }^{28}$, teve importante e destacada atuação no planejamento do Tratado de Madrid, já que era membro do Conselho Ultramarino e Escrivão da Puridade (secretário) do rei Dom João V.

O Tratado de Madri, assinado em 13 de janeiro de 1750, consagrou o princípio do uti possidetis, revogando o meridiano de Tordesilhas e reconhecendo a expansão portuguesa. No Sul, o tratado determinou a entrega de Sacramento à Espanha, uma vez que a campanha uruguaia era de colonização castelhana. À guisa de compensação, Portugal receberia, além do reconhecimento à ocupação portuguesa no Rio Grande, os Sete Povos das Missões. Os jesuítas seriam evacuados para suas reduções de Missiones e Corrientes. $^{29}$

No ano de 1750, outros fatos importantes ocorreram na Europa, e com reflexos diretos no Brasil: a Coroa Portuguesa passa para Dom José I, que sucedeu de Dom João V; a nomeação por Dom José de Sebastião José de Carvalho e Melo, o futuro marquês do Pombal, como primeiro-ministro, conferindo-lhe plenos poderes; as medidas adotas por Pombal para fortalecer o poder real;

Antes da sua confirmação definitiva, ocorrida em Badajoz ${ }^{30}$, ocorreram Tratados intermediários: o Tratado de El Pardo, o Tratado de Paris e o Tratado de Santo Ildefonso. A

\footnotetext{
${ }^{28}$ Ministro do Conselho de Ultramar e secretário particular de d. João V, o brasileiro Alexandre de Gusmão (1695-1753). Seu nome de batismo era Alexandre Lourenço Rodrigues, natural da vila de Santos. Estudou em Cachoeira e Salvador, na Bahia, cursando Humanidades, Artes, Filosofia e Retórica. Adotou o nome de seu parente e protetor Alexandre de Gusmão, jesuíta fundador e diretor do Seminário de Belém (Cachoeira). Aos 15 anos, embarcou para Lisboa, influenciado pelo seu irmão, o padre Bartolomeu Lourenço de Gusmão, inventor do balão esférico. Formou-se em Direito e doutorou-se pela Universidade de Coimbra, e Jurisprudência, pela de Paris. Desempenhou atividades diplomáticas na França e Roma. Como secretário de $d$. João V e ministro do Conselho Ultramarino, teve uma função estratégica na assinatura do Tratado de Madri, sendo o autor de sua minuta, orientador do ministro português na Espanha, e seu apologeta frente aos opositores lusitanos. Parte dessa polêmica foi mantida com o ex-governador da Colônia do Sacramento, Antônio Pedro de Vasconcellos, que criticava o tratado. Fruto deste debate, Gusmão revelou o movimento estratégico de retirada do Prata frente ao interesse inglês de instalar ali uma Feituria (Campanha del Brasil, 1939, t. 2, p.16). GOLIN, op. cit. 1999, p.168.

${ }^{29}$ KERN, op. cit., p.172.

${ }^{30}$ O Tratado de Badajoz, assinado em 1801, entre Portugal e Espanha, consagrava o domínio português sobre as Missões. Segundo Pesavento, a "França napoleônica e Inglaterra que disputavam mercados, envolvem nas
} 
Colônia do Sacramento e as Missões passam à Espanha e Portugal fica com a Ilha de Santa Catarina. O território de São Pedro do Rio Grande fica cortado ao meio, no sentido longitudinal, passando o limite pelas imediações da atual cidade de Santa Maria; o Tratado de Badajoz (1801) colocou fim à nova guerra entre Portugal e Espanha (Guerra das Laranjas) reafirmando finalmente, o Tratado de Madrid. Antes, os luso-brasileiros haviam invadido os Sete Povos das Missões Orientais, expulsando os espanhóis, aquilo o que foi conquistado continuou com o domínio português. As fronteiras da Capitania com as possessões espanholas, a oeste, ficaram sendo praticamente com o recorte atual, exceto os atuais e vigentes limites com o Uruguai.

O Tratado de Madrid, que foi acordado para terminar de certa forma com a série de conflitos resultantes de disputas territoriais, mas ao invés de acabar com eles, acabou acarretando em mais lutas e conflitos.

\section{A GUERRA GUARANÍTICA}

Após a ascensão de Fernando VI ${ }^{31}$ e D. Maria Bárbara de Bragança, filha do rei português D. João V ao trono espanhol, é quando as monarquias ibéricas tentaram através de um acordo diplomático pôr fim a uma série de conflitos relativos às possessões territoriais entre ambos. As negociações diplomáticas com o intuito de ajustar um Tratado de Limites foram iniciadas em 1746. Para tratar das negociações diplomáticas foram nomeados como

hostilidades Espanha e Portugal". PESAVENTO, Sandra Jatahy. História do Rio Grande do Sul. Porto Alegre: Mercado Aberto, 1984. p.32.

${ }^{31}$ Fernando VI (1713-1759). Em 1746, sucedeu ao seu pai, Felipe V, da dinastia dos Bourbon, casado com Maria Luisa de Saboya. Apelidado de El Justo, procurou fazer um reinado de estabilidade. Com a paz de Aquisgrán, que terminou com a Guerra da Itália, Fernando VI assegurou o trono de Nápoles e da Sicília (as Duas Itálias) ao seu irmão Carlos VII, filho de segundo casamento de Felipe V, com Isabel de Farnesio, de Parma, o qual viria a ser seu sucessor na Espanha, com o título de Carlos III, e os ducados de Parma e Plasencia ao seu outro irmão Felipe. Fernando VI casou com Maria Bárbara de Bragança (1711-1758), filha de João V, rei de Portugal, e de Maria Ana, da Áustria. Com a morte da rainha, em 1758, retirou-se ao castelo de Villaviciosa de Odón, onde "morreu de tristeza", um ano depois. CODOLÁ, Manuel Rodríguez. Historia de Espana y los pueblos hispanoamericanos hasta su independencia. Barcelona: Segui, t. terceiro, p.181. Os casamentos cruzados entre as dinastias dos Bourbons e Braganças ibéricos materializaram interesses geopolíticos sobre os quais se pode ter uma visão nos reinados de Felipe V e João V. No dia 19 de janeiro de 1729, literalmente cruzaram seus casais de filhos em pomposas e deslumbrantes festividades. Os príncipes Fernando e Mariana Vitória, da Espanha, uniram-se em matrimônio com Maria Bárbara de Bragança e d. José, de Portugal. GOLIN. Op.cit. 1999. p.16. 
representantes da política exterior dos países ibéricos, D. José Carvajal y Lancaster ${ }^{32}$ pela Espanha e o brasileiro Alexandre de Gusmão por Portugal.

\begin{abstract}
A Espanha, em paz com Portugal, através dos casamentos reais, só tinha a temer a poderosa França como país limítrofe. A riqueza e o poderio da Espanha vinham de suas ricas colônias na América. Portugal não era poderoso, mas era tão rico como a Espanha, com seus domínios na Brasil, verdadeiro armazém que não se podia conquistar, embora fosse possível alcançar com o comércio recíproco, garantido pelos casamentos das Casas Reais Ibéricas. ${ }^{33}$
\end{abstract}

As Coroas Ibéricas reconheciam que haviam ultrapassado seus limites territoriais determinados pelo recorte proposto do Tratado de Tordesilhas. Segundo entendimentos entre ambas, Portugal havia expandido seus domínios na América do Sul, principalmente numa região de grande importância, a do estuário rio da Prata, a partir da fundação estratégica da Colônia do Santíssimo Sacramento, e a Espanha havia irregularmente expandido seus domínios em outros territórios, como por exemplo, nas ilhas Filipinas.

(...) O reconhecimento da posse efetiva dos espaços conquistados por Portugal e a Espanha e a idéia de compensação por troca desses espaços ganhava força. Assim, pelo princípio de uti possidetis Portugal reconhecia à Espanha a posse das ilhas Filipinas, enquanto a Espanha legitimava a posse do vale do Rio Amazonas, as regiões de Vila Bela e Cuiabá para Portugal. Entretanto, por ser também requerida a idéia de continuidade, após levantamentos e propostas por parte dos dois ministros as atenções para as definições territoriais recaíram sobre a região do Prata. Portugal aceitava ceder a Colônia do Sacramento, e, consequientemente, o domínio, sobre a bacia do Prata, em troca da margem oriental do rio Uruguai. Afinal, as Missões jesuíticas dos guaranis, mais especificamente a zona dos Sete Povos, segundo o historiador Décio Freitas, era um bolsão espanhol a impedir a unificação de terras portuguesas. ${ }^{34}$

Gomes Freire foi o incumbido para a tarefa de conquistar e ocupar definitivamente a área que abrangia os Sete Povos das Missões Orientais e assegurando assim para Portugal a posse definitiva desta nova possessão, onde durante sete longos anos, os índios missioneiros defenderam e atacaram as comissões demarcadoras como à única maneira de se manterem em seus territórios.

\footnotetext{
${ }^{32} \mathrm{D}$. José de Carvajal y Lancaster, ministro de estado de Fernando $\mathrm{VI}$, enviou à corte de Lisboa seu memorial de julho de 1747, estabelecendo os primeiros elementos para o tratado de limites entre as coroas ibéricas. Carvajal orientava a política externa da Espanha em função das alianças, buscando manter um equilíbrio entre a Inglaterra e a França.

${ }^{33}$ FLORES. 1983. op. cit., p. 63.

${ }^{34}$ GOULART, 2004. op. cit., p.83
} 
Os jesuítas apesar das determinações expressas dos reis de Portugal e Espanha e do padre Altamirano, Representante Geral da Companhia de Jesus, mantiveram-se ao lado dos índios missioneiros.

\begin{abstract}
A relutância dos jesuítas em se retirar dos Sete Povos tem sido apontada como a principal causa da ferrenha campanha de Pombal contra eles. É preciso, porém, considerar as nuances da questão. Em primeiro lugar, a desafeição aos jesuítas em Portugal e na Espanha vinha de antes. (...) A resistência partiu dos padres missionários e dos indígenas, esperando que com sua recusa à mudança fizessem o governo espanhol desfazer o tratado. Quanto mais se dilatar esta execução tanto mais seguro estaremos de que não se fará mais, pois não quer El Rei que, com violência, se mudem os índios e se lhes tirem os bens e muito menos com força armada. (padre Pascino, 1752). ${ }^{35}$
\end{abstract}

Portanto, os padres jesuítas permaneceram todo o tempo ao lado dos índios missioneiros e ainda organizaram suas resistências, apesar das ordens reais lusitanas e espanholas, e do padre Altamirano que acompanhou o Val de Lírios para que retirassem do território os povos missioneiros e partissem para outro local sob jurisdição espanhola.

No entanto os jesuítas alegaram que era um prazo muito escasso para a execução que toda esta complexa situação requeria, pois também acreditavam numa reversão de expectativas, pelo fato de terem importantes aliados na Europa e que trabalhavam com o intuito de cancelarem a troca feita pelas Coroas Ibéricas, e que os padres tentaram de todas as formas se manterem nos territórios missioneiros e que segundo Arthur Velhinho argumenta:

\begin{abstract}
A organização jesuítica, além de empresa religiosa, social e econômica, constituía a maior potência militares das dependências platinas, senão da América do Sul. Tamanha força acabaria despertando inquietação na própria Espanha. Afinal, o que se via, o que os padres constantemente alardeavam, é que as possessões espanholas tributárias do Prata viviam militarmente a expensas da Companhia. Não seria oportuno pôr cobro a esta situação, antas que ela derivasse para rumos imprevistos? Até quando a Província do Paraguai, com seus Trinta Povos aguerridos, consentiria em manter-se fiel à vassalagem dos reis católicos?. ${ }^{36}$
\end{abstract}

Os Guarani através da liderança do cacique Sepé Tiaraju, e também com o apoio de alguns jesuítas que acreditavam na reversão do tratado, tentaram retardar o máximo possível o translado. Porém, ambas as Coroas tinham pressa em efetivar o Tratado, e nomearam comissões para colocar em prática as determinações contidas no acordo. Diante impossibilidade de haver uma revogação, que somente ocorreu após o término do conflito e

\footnotetext{
${ }^{35}$ KERN, op. cit., p. 173.

36 VELHINHO, Arthur. Os jesuítas no Rio Grande do Sul. In: Fundamentos da Cultura Rio-Grandense.

Porto Alegre: UFRGS, 1960, vol. 4, p. 115.
} 
que acabou por gerar a destruição por completo o sistema missional jesuítico implementado pelas reduções, partiram para o enfrentamento com as Coroas Ibéricas, que já tinham estruturado um acordo de ajuda mútua na ilha de Martin Garcia $^{37}$, em caso de resistência por parte das comunidades missioneiras.

\begin{abstract}
No dia 3 de outubro de 1754, o exército colonial espanhol teve o primeiro confronto armado com os índios, que interceptaram sua marcha perto do rio Daymal, para "defender suas terras de Misiones" conforme o Manifesto de Andonaegui: "gritaram os índios com insolência", formaram em meio círculo, com bandeiras e estandartes, e demonstrações de atacar. O general mandou unir três partidas [destacamentos] e preparar outras tropas de reforço, caso fosse necessário. E ordenou o ataque, deixando 230 índios mortos, e fazendo 72 prisioneiros. Os missioneiros eram comandados pelo cacique Rafael Paracatu, que, junto com outros prisioneiros, foram mandados, embarcados, para Buenos Aires. ${ }^{38}$
\end{abstract}

No ano de 1754, ocorreu o primeiro dos vários confrontos armados entre os Guarani reduzidos com as tropas conjuntas do português Gomes Freire e do espanhol José Andonaegui no território uruguaio, perto da atual cidade de Colônia.

Os confrontos entre as forças conjuntas ibéricas com os Guarani culminam mais tarde com a chamada Chacina de Caiboaté, onde foram mortos centenas de missioneiros, numa luta marcada pela desigualdade militar entre ambos, pois os Guarani contavam com poucas armas de fogo, ao contrário dos luso-espanhóis que além de soldados bem treinados, contavam com um grande aparelhamento bélico.

A desorganização dos índios missioneiros, no enfrentamento contra os exércitos português e espanhol, sem um comando único, acabou favorecendo os ibéricos, pois não conseguiram resistir por muito tempo às táticas militares dos aliados europeus. A partir deste confronto, os comissários de Portugal e de Espanha, decidiram colocar em prática, aquilo que havia sido anteriormente decidido no caso de haver por parte dos Guarani reações contrárias ao Tratado, isto é, unir seus exércitos para o enfrentamento com os missioneiros, deflagrando a guerra em 1756.

\footnotetext{
${ }^{37}$ (...) foi ali que se encontraram, em 15 de julho de 1753, o comandante espanhol José Andonaegui e o português Gomes Freire de Andrade, ocasião em que "resolveram levar a guerra às Missões caso a mudança dos Sete Povos não fosse feita em um mês". PORTO, História das Missões Orientais do Uruguai- Segunda Edição Revista e Melhorada pelo p. Luís Gonzaga Jaeger S.J. - Livraria Selbach, Porto Alegra, s/data - Segunda Parte, p.215.

${ }^{38}$ GOLIN, 1999. op. cit., p. 334.
} 
A partir do momento em que os povoados missioneiros deflagraram guerra aos ibéricos, que ficou conhecida como a "Guerra Guaranítica" ${ }_{39}$, foram travadas inúmeras batalhas e enfrentamentos, que só terminaria com o aniquilamento dos guaranis e a morte de Sepé Tiaraju, fato este ocorrido no entardecer do dia 7 de fevereiro de 1756, no atual município de São Gabriel (RS) junto a Sanga da Bica.

A morte do principal líder missioneiro, Sepé Tiaraju que detinha o posto de corregedor e alferes real de São Miguel, ocorreu numa das primeiras batalhas. Enquanto os guaranis enfrentaram os soldados das Coroas ibéricas, soldados estes, treinados e muito bem armados e com um comando único, forte e centralizado, utilizando somente lanças, arcos, flechas e, umas poucas armas de fogo, sucumbiram diante o poderio dos exércitos ibéricos, que detinham inúmeros canhões e soldados que portavam armas de fogo. Três dias depois da morte de Sepé, os Guarani sofreram sua derradeira derrota: a chacina de Caiboaté. Era o fim da resistência guaranítica

Após este massacre, o que se viu a seguir foi à ocupação das povoações missioneiras, que ao abandonar as reduções jesuíticas passaram colocar fogo em tudo que ficava para trás, destruindo aquilo que por muitos anos fora construído e mantido em conjunto pelos Guarani e pelos padres jesuítas da Companhia de Jesus.

Depois de certa resistência, um a um dos povoados missioneiros através de seus cabildos $^{40}$ e dos padres foram se rendendo e prestando obediência aos comandantes das forças portuguesas e espanholas. Se por um lado a ordem de desocupação das terras em questão foi cumprida, porém foram os exércitos portugueses e os espanhóis que fizeram a transmigração dos povos missioneiros para o lado ocidental do rio Uruguai, mas desta vez, diferentemente do que havia sido acordado anteriormente no Tratado de Madrid, confiscaram quase todos os pertences dos Guarani.

Desde o início da fundação da Colônia do Santíssimo Sacramento, as forças espanholas utilizaram exércitos Guarani proveniente da região das Missões para derrotar e

\footnotetext{
39 Nome que se dá aos violentos conflitos que envolvem os índios guaranis e as tropas espanholas e lusobrasileiras no sul do Brasil após a assinatura do Tratado de Madri, em 1750. Os guaranis dos Sete Povos das Missões recusaram-se a deixar suas terras no território do Rio Grande do Sul e a transferir-se para o outro lado do rio Uruguai, conforme ficara acertado no acordo de limites entre Portugal e Espanha. Fonte: www.terrabrasileira.net. Acesso em 01/08/2017.

${ }^{40}$ Simbolizava o poder e a superioridade de um estrato social mais elevado entre os Guarani, usado como elemento de ligação entre o jesuíta e os demais estratos da população. QUEVEDO; GOMES, 2003. op. cit., p.44.
} 
expulsar, por diversas vezes, os portugueses, e isso também acabou sendo levado em conta quando as duas Coroas responsabilizaram os jesuítas da Companhia de Jesus, que terminaram sendo expulsos dos dois impérios ibéricos.

Em 1757, um ano depois da fatídica batalha, e com a chegada de Val de Lírios, conforme a carta enviada por Gomes Freire criou-se um impasse, pois este não desejava entregar a Colônia do Santíssimo Sacramento antes dos espanhóis evacuassem totalmente as Missões Orientais, pois acreditava que os espanhóis deixariam os portugueses a sua própria sorte em relação à retirada dos missioneiros conforme relata e previa parte da carta abaixo:

Se não obstante, S. M. me mandar (que) me entregue dos Povos no risco de ficar com uma Guerra ou contínua incomodidade, o cumprirei como devo; mas rogo aos pés de S. M. sejam a tão decisivas e claras as ordens que sem mais questões se lhe dê inteira execução ao que nos for decretado ${ }^{41}$

O exército luso após ter permanecido por cerca de dez meses nas Missões, regressa a Rio Pardo, e que segundo alguns analistas, "obedecia a uma visão estratégica evidente" ${ }^{42}$, pois se houvesse um rompimento com o exército espanhol, não comprometeria suas melhores tropas coloniais.

Apesar do abandono das Missões Jesuíticas Orientais, os Guarani continuaram com a sua resistência contra os exércitos ibéricos, isso aliado com a morte de Carvajal e a retirada do comandante Gomes Freire para o Rio de Janeiro, que deixou apenas um pelotão em Rio Grande para dar sustentação e retaguarda aos demarcadores, fato este que acabou por enfraquecer a ação destes no processo demarcatório.

Pombal, que estava no auge de seu prestigio perante o rei de Portugal, continuou firme no seu propósito de anexar definitivamente às terras missioneiras e de iniciar uma perseguição oficial a Companhia de Jesus e seus representantes. Em 1759, Pombal, através de um decreto, expulsou os padres jesuítas ${ }^{43}$ das terras pertencentes ao reino português, o que

\footnotetext{
${ }^{41}$ Ver: Carta de Gomes Freire a Pombal, datada de 15 de maio de 1757. Anais da Biblioteca Nacional, 71, p. 103.

${ }^{42}$ Ver: Anêmona Xavier Bastos, do SPHAN, $n^{\circ} 5$ e gen. F. de Paula Cidade, Síntese de Três Séculos de Literatura Militar Brasileira.

43 A Expulsão dos Jesuítas: Lei dada em 3 de setembro do mesmo ano [de 1759], para a proscrição, desnaturalização e expulsão dos sobreditos regulares, neste reino e seus domínios. D. José, por graças de Deus rei de Portugal e dos Algarves, d’aquém e d’além mar. D. José, por graça de Deus rei de Portugal e dos Algarves, d’aquém e d’além mar em África, senhor da Guiné e da conquista, navegação e comércio da Etiópia, Arábia, Pérsia, e da Índia etc. Faço saber que, havendo sido infatigáveis a constantíssima benignidade e a religiosíssima clemência com que, desde o tempo em que as operações que se praticaram para a execução do tratado de limites de conquista, ... procurei aplicar todos os meios quanto a prudência e a moderação podiam
} 
abriu procedência aos demais reinos a expulsarem também de seus domínios a ordem jesuítica. Em 1767, os jesuítas seriam expulsos também da França e da Espanha e, em julho de 1773, o papa Clemente XIV extinguiria a Companhia de Jesus. Pombal tinha conseguido atingir um dos seus objetivos que era a tentativa de desestruturar a ordem jesuítica.

Pombal pouco pode aproveitar seu triunfo, pois depois de quatro anos da expulsão dos jesuítas, morreu D. José I, o seu protetor e ascendeu ao trono português, D. Maria I ${ }^{44}$, a "rainha louca". A partir deste momento, Pombal começou a cair em desgraça e após sua morte em 1782, seu corpo ficou mais de meio século abandonado na cripta da quinta em qual havia permanecido durante o seu exílio, sendo que somente em 1836, finalmente foi sepultado em Lisboa.

A ascensão de Carlos III, após a morte de Fernando VI, ao trono espanhol, ocorreu uma retomada da Espanha em relação às áreas em questão, pois se considerava envolvida pelas artimanhas e métodos ardilosos empregados pela diplomacia portuguesa. A execução do Tratado de Madrid foi suspensa em 1760, apesar do marquês de Pombal tentar costurar um

sugerir para que o governo dos regulares da Companhia denominada de Jesus, das províncias destes reinos e seus domínios, se apartasse do temerário e façanhoso projeto com que havia intentado e clandestinamente prosseguido a usurpação de todo o Estado do Brasil, ... depois de ter ouvido os pareceres de muitos ministros doutos, religiosos, e cheios de zelo da honra de Deus, e do meu real serviço, decoro, e do bem comum dos meus reinos e vassalos, que houve por bem consultar, e com os quais fui servido conformar-me: declaro os sobreditos regulares na referida forma corrompidos, deploravelmente alienados do seu santo instituto e manifestamente indispostos com tantos e tão abomináveis, tão inveterados e tão incorrigíveis vícios, para voltarem à observância dele, por notórios rebeldes, traidores, adversários e agressores que têm sido e são atualmente contra a minha real pessoa e Estados, contra a paz pública dos meus reinos e domínios, e contra o bem comum dos meus fiéis vassalos: ordenando que como tais sejam tidos, havidos e reputados e os hei, desde logo, em efeito desta presente lei, por desnaturalizados proscritos e exterminados: mandando que efetivamente sejam expulsos de todos os meus reinos e domínios, para neles não mais poderem entrar ... $\mathrm{E}$ para que esta minha lei tenha toda a sua cumprida e inviolável observância, e se não possa nunca relaxar pelo lapso do tempo em comum prejuízo uma tão memorável e necessária disposição, estabeleço que as transgressões dela fiquem sendo casos de devassa ... Em A. J. de Melo Morais. História dos jesuítas e suas missões na América do Sul. Rio de Janeiro: Casa Imperial de E. Dupont, 1872, p. 587-590.

${ }^{44}$ Foi a primeira rainha em Portugal a exercer o poder efetivo. Seu primeiro ato como rainha, iniciando um período que ficou conhecido como Viradeira, foi a demissão e exílio da corte do Marquês de Pombal, a quem nunca perdoara a forma brutal como tratou a família Távora durante o Processo dos Távoras. Rainha amante da paz, dedicada a obra sociais, concedeu asilo a numerosos aristocratas franceses fugidos ao terror da Revolução Francesa (1789). Mentalmente instável, desde 10 de fevereiro de 1792 foi obrigada a aceitar que o filho tomasse conta dos assuntos de Estado. Obcecada com as penas eternas que o pai estaria sofrendo no inferno, por ter permitido a Pombal perseguir os jesuítas, o via como "um monte de carvão calcinado". Em 1799, sua instabilidade mental se agravou com os lutos pelo seu marido D. Pedro III (1786) e seu filho, o príncipe herdeiro José, Duque de Bragança, Príncipe da Beira, Príncipe do Brasil, morto aos 26 anos (1788), a marcha da Revolução Francesa, e execução do Rei Luís XVI de França na guilhotina e o filho e herdeiro João assumiu a regência: D. João VI de Portugal. file:///G:/Maria I de Portugal.htm. Acesso em 24/09/2017. 
novo acordo diplomático entre as Coroas Ibéricas. Após o cancelamento do Tratado, a Espanha nomeou administradores leigos, já que os jesuítas haviam sido expulsos dos domínios espanhóis, e retomou o controle efetivo das áreas missioneiras, tudo submetido ao controle central do governo de Buenos Aires.

A Espanha neste período encontrava-se fortalecida politicamente, já Pombal sofreu um duro revés com a Viradeira ${ }^{45}$ em 1777, o que o levou a rainha-mãe, D. Maria, condenar tudo aquilo havia sido obra do marquês. Aproveitando a situação em que esta fortalecida politicamente a Espanha negocia com Portugal um novo Tratado, neste contexto surge o Tratado de Santo Ildefonso ${ }^{46}$, que redefiniu as fronteiras entre Portugal e a Espanha, e que pelo novo recorte geográfico, tanto a Colônia do Santíssimo Sacramento como os Sete Povos das Missões Orientais passaram a pertencer ambas a Espanha.

A questão fronteiriça do sul do continente acabou só sendo resolvida definitivamente por um novo acordo em 1801, o Tratado de Badajós, e seu epilogo é descrito por Darcy Ribeiro $^{47}$ :

Elas foram "assaltadas pela burocracia colonial, pelos assuncenos e pelos mamelucos paulistas, propositadamente desorganizadas para abolir características tidas como comunizantes. Já em fins do século XVIII, os índios missioneiros haviam sido dispersados, escravizados e conduzidos a regiões longínquas, dissolvidos no mundo dos gaúchos, ou ainda, refugiados nas matas onde se esforçavam por reconstituir a vida tribal, enquanto suas terras e seu gado passavam às mãos de novos donos".

Daí por diante, é crível dizer que a geopolítica empreendida pelas Coroas Ibéricas potencializa uma análise mais profunda e abrangente dos processos emancipatórios e

\footnotetext{
${ }^{45}$ Viradeira é a designação que se dá ao período que se iniciou 13 de março de 1777 com a nomeação de D. Maria I de novos Secretários de Estado, em substituição do marquês de Pombal. Neste período uma progressiva quebra do controle estatal sobre muita das áreas econômicas, com a extinção de alguns dos monopólios mercantis estabelecidos por Pombal, e permitiu-se uma retomada da influência da Igreja da alta nobreza sobre o Estado. Muitos dos presos políticos foram libertados e muitos nobres reabilitados, incluindo alguns a título póstumo. No que se refere a Universidade de Coimbra, muitos professores e alunos foram expulsos sob diversas acusações ligadas à heresia, como enciclopedismo, naturalismo e deísmo. Francisco de Melo Franco, um dos expulsos, escreveu O Reino da Estupidez em represaria. File:///G:/Viradeira.htm. Acesso em 24/08/2017.

${ }^{46}$ Logo no início de seu reinado, assinou o Tratado de Santo Ildefonso, que restituiu à Espanha a Colônia do Santíssimo Sacramento, enclave português no sul do Uruguai. Ainda no campo das relações exteriores, completou os ajustes fronteiriços entre o Brasil e as colônias espanholas do Prata, de acordo com as cláusulas do Tratado do Pardo. file:///G:/maria.htm. Acesso em 24/08/2017.
}

\footnotetext{
${ }^{47}$ Fonte: www.terrabrasileira.net. Acesso em 22/08/2017.
} 
determinantes na construção e desconstrução de alguns paradigmas da América Colonial. Ademais a ação espanhola na tentativa de construir dois grandes centros de organização de populações indígenas e que se transformaram num primeiro momento como fator delineador das fronteiras ibéricas, para posteriormente ser palco de profundas transformações socioculturais e econômicas da América do Sul. Concluí então que as Missões Jesuíticas foram sem dúvida algo muito significativo e de valor inestimável na construção de um novo espaço e de identidades locais e nacionais.

\section{CONSIDERAÇÕES FINAIS}

É necessário inicialmente destacar que o processo das definições das fronteiras permeou a geopolítica ibérica no Sul do Continente Americano durante o final do século XVII e o século XVIII, em relação à construção da identidade histórica da população e na consolidação dos Estados Nacionais do estremo sul das Américas, chegando a estremecer profundamente a relações diplomáticas entre ambas as Coroas. Relações estas que inclusive tiveram muitas nuances, das quais podem ser percebidas através dos casamentos reais e dos acordos assinados e revogados entre portugueses e espanhóis.

No mais consideramos que a fundação da Colônia do Sacramento conseguiu transformar uma região até então inóspita (atual RS), em uma importante e estratégica área do ponto de vista econômica e política, onde os conflitos entre as Coroas Ibéricas, em virtude de que as disputas territoriais e econômicas na região platina eram constantes, pois era imperativo naquele momento marcar presença naquela área, em razão da sua importância comercial e estratégica em função do grande contrabando praticado no rio da Prata. É neste contexto que se institui a importância da fundação da Colônia do Santíssimo Sacramento.

Eis então; um dos motivos pelos quais muitos investigadores concordam ser o Tratado de Madrid, sem dúvida o mais emblemático e o que mais acarretou conflitos entre os dois países ibéricos. Concluí então que o já referido tratado, foi sem dúvida o fator preponderante na desconstrução do espaço missioneiro, quando da troca da Colônia do Santíssimo Sacramento pelos Sete Povos das Missões Orientais. Vê-se por consequência que muito mais do que os limites entre os dois domínios estavam em jogo, pois, enquanto que a Espanha tinha como principal objetivo garantir a navegação exclusiva no rio da Prata, também poderia através deste acordo conter o avanço português rumo às minas de Potosi, e 
Portugal além de livrar-se de um enclave altamente dispendioso anexou uma grande e importante área aos seus domínios.

A tentativa das monarquias ibéricas de executarem o acordo diplomático através do Tratado de Madrid, tinha como intuito pôr fim a uma série de conflitos relativos às possessões territoriais entre ambos. Ocorreram várias tentativas de manutenção do status quo por parte dos missioneiros, algo que não se efetivou em função dos interesses ibéricos para suas colônias no sul do Continente Americano. Por fim visualiza-se que as reações contrárias geradas a partir da não aceitação do cumprimento do acordo real, expressas através da Guerra Guaranítica, aliada a desproporcionalidade bélica e estrutural entre os conflitantes, tornou-se preponderante no aspecto global, o resultado advindo dos embates nas reduções jesuíticas e que acabaram contribuindo categoricamente para o epílogo missioneiro, concretizado mais tarde pela expulsão dos jesuítas da Companhia de Jesus dos domínios de Espanha e Portugal.

\section{REFERÊNCIAS BIBLIOGRÁFICAS}

CAMARGO, Fernando. Britânicos no Prata: caminhos da hegemonia. Série Ciência História. Passo Fundo: EDIUPF, 1996.

COLVERO, Ronaldo. Negócios na madrugada: o comércio ilícito na fronteira do Rio Grande do Sul. Passo Fundo: UPF, 2004.

DIEHL, Astor Antônio. Do Método Histórico. Passo Fundo: EDIUPF, 1997.

FLORES, Moacyr. Colonialismo e Missões Jesuíticas. Porto Alegre: EST / Instituto de Cultura Hispânica do Rio Grande do Sul, 1983.

GOLIN, Tau. A Fronteira / Luis Carlos Golin. Porto Alegre: L\&PM, 2002.

. A Guerra Guaranítica: como os exércitos de Portugal e Espanha destruíram os

Sete Povos dos jesuítas e índios guaranis no Rio Grande do Sul (1750-1761). Passo

Fundo/Porto alegre: EDIUPF/Editora da Universidade - UFRGS, 1999.

GOMES, Roselene Moreira; QUEVEDO, Júlio. São Nicolau. Porto Alegre: Martins Livreiro, 2003, p.54.

GOULART, Cátia Rosana Dias. Uma Leitura de A Cidade dos Padres no Contexto do Novo Discurso Ficcional-Histórico na América Latina. Fundação Universidade Federal do Rio Grande, 2004.

MONTEIRO, Jonathas da Costa Rego. A Colônia do Sacramento. Porto Alegre: Globo, 1937. I vol. 
KERN, Arno Alvarez. Missões: uma utopia política. Série Documenta 14. Porto Alegre: Mercado Aberto, 1982.

- Utopias e Missões Jesuíticas. Síntese Universitária - 40. Porto Alegre: Ed. Universidade/UFRGS, 1994.

MAURER, Rodrigo. Do um que não sete: o caso da antiga redução de San Francisco de Borja e a dinâmica da diferença. PPG em História UPF, 2011.

PESAVENTO, Sandra Jatahy. História do Rio Grande do Sul. Porto Alegre: Mercado Aberto, 1984.

PINTO, Muriel \& MAURER, Rodrigo. Quando a geo-história avança sobre os significados de um espaço-urbano: as paisagens culturais e as transformações identitárias da fronteira BrasilArgentina. In: Eure. Vol. 40, n. 120. 2014.

PORTO, Aurélio. História das Missões Orientais do Uruguai. Vol. II, III e IV. Porto Alegre: Selbach, 1954.

VELHINHO, Arthur. Os jesuítas no Rio Grande do Sul. In: Fundamentos da Cultura Rio-Grandense. Porto Alegre: UFRGS, 1960, vol. 4. 